\title{
Dendropanax morbifera Léveille extract facilitates cadmium excretion and prevents oxidative damage in the hippocampus by increasing antioxidant levels in cadmium-exposed rats
}

Woosuk Kim', Dae Won Kim², Dae Young Yoo', Hyo Young Jung ${ }^{1}$, Sung Min Nam¹, Jong Whi Kim', Soon-Min Hong ${ }^{3}$, Dong-Woo Kim ${ }^{3}$, Jung Hoon $\mathrm{Choi}^{4}$, Seung Myung Moon ${ }^{5}$, Yeo Sung Yoon ${ }^{1}$ and In Koo Hwang ${ }^{1 *}$

\begin{abstract}
Background: Dendropanax morbifera Léveille is used in herbal medicine as a cancer treatment. In this study, we investigated the effects of Dendropanax morbifera stem extract (DMS) on cadmium (Cd) excretion from the blood and kidney and brain tissues of rats exposed to cadmium, as well as the effects of DMS on oxidative stress and antioxidant levels in the hippocampus after $\mathrm{Cd}$ exposure.

Methods: Seven-week-old Sprague-Dawley rats were exposed to $2 \mathrm{mg} / \mathrm{kg}$ of cadmium by intragastric gavage and were orally administered $100 \mathrm{mg} / \mathrm{kg}$ of DMS for 4 weeks. Animals were sacrificed and Cd determination was performed using inductively coupled plasma mass spectrometry. In addition, the effects of $\mathrm{Cd}$ and/or DMS on oxidative stress were assayed by measuring reactive oxygen species production, protein carbonyl modification, lipid peroxidation levels, and antioxidant levels in hippocampal homogenates.

Results: Exposure to Cd significantly increased Cd content in the blood, kidneys, and hippocampi. DMS treatment significantly reduced $\mathrm{Cd}$ content in the blood and kidneys, but not in the hippocampi. Exposure to $\mathrm{Cd}$ significantly increased reactive oxygen species production, protein carbonyl modification, lipid peroxidation, total sulfhydryl content, reduced glutathione content, and glutathione reductase activity. In contrast, $\mathrm{Cu}$, Zn-superoxide dismutase (SOD1), catalase (CAT), glutathione peroxidase (GPx), and glutathione-S-transferase (GST) activity in the hippocampus were significantly decreased after exposure to $\mathrm{Cd}$, and administration of DMS significantly inhibited these Cd-induced changes.
\end{abstract}

Conclusion: These results indicate that DMS facilitates cadmium excretion from the kidneys, reduces cadmium-induced oxidative stress in the hippocampus, and modulates SOD1, CAT, GPX, and glutathione-S-transferase activities.

Keywords: Dendropanax morbifera extract, Cadmium, Hippocampus, Oxidative stress, Antioxidants

\section{Background}

Dendropanax morbifera Léveille is mainly distributed in southwestern Korea. This tree was initially used for the production of golden varnish [1], but the leaves, stems, roots, and seeds contain compounds that are used in traditional medicine for the treatment of skin and

\footnotetext{
* Correspondence: vetmed2@snu.ac.kr

'Department of Anatomy and Cell Biology, and Research Institute for Veterinary Science, College of Veterinary Medicine, Seoul National University, Seoul 151-742, South Korea

Full list of author information is available at the end of the article
}

infectious diseases, headaches, and other maladies [2]. The polyacetylene compounds in Dendropanax morbifera leaves have anti-complement, anti-diabetic, and anti-atherogenic activities [1,3-5].

Cadmium (Cd) is one of the most harmful heavy metals in nature and it is released into the environment through mining and smelting. The main sources of $\mathrm{Cd}$ exposure include production of certain types of batteries, intake of contaminated food and water, and inhalation of tobacco smoke or polluted air [6,7]. Cd exposure generates free radicals such as superoxide radicals, hydroxyl radicals,

\section{Ciomed Central}

(c) 2014 Kim et al.; licensee BioMed Central Ltd. This is an Open Access article distributed under the terms of the Creative Commons Attribution License (http://creativecommons.org/licenses/by/4.0), which permits unrestricted use, distribution, and reproduction in any medium, provided the original work is properly credited. The Creative Commons Public Domain Dedication waiver (http://creativecommons.org/publicdomain/zero/1.0/) applies to the data made available in this article, unless otherwise stated. 
and nitric oxide [8]. Free radical accumulation in animals is harmful to tissue types in many organs, including the brain and spinal cord. The nervous system is highly susceptible to damage induced by free radicals because nervous tissue contains high levels of unsaturated fatty acids and iron [9]. Cd exposure induces oxidative DNA damage due to excess oxygen-derived free radicals $[10,11]$ and depletes antioxidant levels, resulting in a state of oxidant/ antioxidant imbalance. Therefore, modulation of antioxidant levels in the brain may be an effective strategy with which to reduce $\mathrm{Cd}$-induced neurotoxicity.

Several approaches have been used to promote or facilitate the excretion of $\mathrm{Cd}$ from the body because it has a long biological half-life (approximately 30 years in humans) and readily accumulates in tissues [12]. Debarked Dendropanax morbifera stem extract (DMS) decreases 2,2-diphenyl-1-picrylhydrazyl radical levels, and its antioxidant capacity is greater than that of other organ extracts from D. morbifera [13]. In addition, rutin, a bioflavonoid isolated from $D$. morbifera, significantly decreases rotenone-induced generation of reactive oxygen species in SH-SY5Y cells and mitochondrial membrane potential depletion [14]. However, there are no reports on the effects of DMS on oxidative stress and antioxidant enzyme activity after $\mathrm{Cd}$ exposure. Therefore, in this study, we investigated the effects of DMS treatment on $\mathrm{Cd}$ excretion from the kidney and hippocampus, and on antioxidant enzyme activity and lipid peroxidation in the hippocampus of $\mathrm{Cd}$-exposed rats.

\section{Methods}

\section{Experimental animals}

Male Sprague-Dawley rats were purchased from Orient Bio Inc. (Seongnam, South Korea). Rats were housed in a conventional animal facility at $23^{\circ} \mathrm{C}$ with $60 \%$ humidity, a $12 \mathrm{~h} / 12 \mathrm{~h}$ light/dark cycle, and free access to food and tap water. The handling and care of the animals conformed to the guidelines established in order to comply with current international laws and policies $(\mathrm{NIH}$ Guide for the Care and Use of Laboratory Animals, NIH Publication No. 85-23, 1985, revised 1996), and were approved by the Institutional Animal Care and Use Committee (IACUC) of Seoul National University (SNU130522-1). All of the experiments were conducted with an effort to minimize the number of animals used and the suffering caused by the procedures used in the study.

\section{Preparation of DMS}

Fresh Dendropanax morbifera Léveille was purchased from a local market on Jeju Island in Korea. The plant was authenticated by two practitioners of traditional Asian medicine, and a voucher specimen was deposited with Egreen Co. Ltd. (deposition number: 2013-001). Stems from the plant samples (100 g) were chopped, blended, soaked in $2 \mathrm{~L}$ of $80 \%$ ethanol, and refluxed three times at $20^{\circ} \mathrm{C}$ for $2 \mathrm{~h}$. The insoluble materials were removed by centrifugation at $10,000 \times g$ for $30 \mathrm{~min}$, and the resulting supernatant was concentrated and freezedried to yield a powder (yield: $4.7 \%$ ). Before each experiment, the dried extract was dissolved in distilled and deionized water.

\section{Administration of Cd and DMS}

Cadmium chloride was obtained from Sigma-Aldrich (St. Louis, MO, USA). Animals were divided into 4 treatment groups ( $n=29$ in each group): a control group, a group treated with $100 \mathrm{mg} / \mathrm{kg}$ DMS, a group treated with $2 \mathrm{mg} / \mathrm{kg} \mathrm{Cd}$, and a group treated with Cd and DMS. Cd and/or DMS were administered orally to 7-week-old rats once a day for 4 weeks.

\section{Cd level in the blood, brain, and kidney}

To measure $\mathrm{Cd}$ concentration in the blood and brain and kidney tissues, control, DMS-, Cd-, and Cd-DMStreated rats ( $n=7$ in each group) were anesthetized with $100 \mathrm{mg} / \mathrm{kg}$ of Zoletil 50 (Virbac, Carros, France) and the blood, hippocampi, and kidneys were extracted. Blood samples were allowed to clot, after which they were centrifuged for $30 \mathrm{~min}$ at $1,000 \mathrm{~g}$ to separate the serum. Hippocampi and kidneys were weighed in glass vessels, and tissues were digested by adding 3-8 $\mathrm{mL}$ of $\mathrm{HNO}_{3}$ at $130^{\circ} \mathrm{C}$ for $3 \mathrm{~h}$, after which $2 \mathrm{~mL}$ of $\mathrm{H}_{2} \mathrm{O}_{2}$ was added and the samples were heated for $1 \mathrm{~h}$. Serum and digested samples were transferred to polypropylene flasks for $\mathrm{Cd}$ determination. $\mathrm{Cd}$ determination was performed by using inductively coupled plasma mass spectrometry (ICP-MS; PerkinElmer Sciex, Thornhill, Canada).

\section{Measurement of reactive oxygen species (ROS) production in the hippocampus}

The effects of $\mathrm{Cd}$ and/or DMS on ROS production in the hippocampus of control, DMS-, Cd-, and Cd-DMStreated rats ( $n=5$ in each group) were assessed using the fluorescent probe $2^{\prime}, 7^{\prime}$-dichlorofluorescin diacetate (DCFH-DA) [15]. Intracellular ROS oxidize DCFH-DA to dichlorofluorescein (DCF), an intense fluorescent chemical. Four weeks after $\mathrm{Cd}$ treatment, rats in each group were deeply anesthetized and euthanized by decapitation. Brain mitochondria were obtained as described previously [16]. Mitochondrial protein quantification was determined by the Bradford method [17] using bovine serum albumin (BSA) as the standard. Mitochondria isolated from different groups $(0.5 \mathrm{mg} / \mathrm{mL})$ were incubated with $10 \mu \mathrm{M}$ DCFH-DA at $37^{\circ} \mathrm{C}$ for $60 \mathrm{~min}$, and the fluorescence intensity of DCF was measured at an excitation wavelength of $488 \mathrm{~nm}$ and emission wavelength of $527 \mathrm{~nm}$ in a microplate reader (SpectraMax M5, Molecular Devices LLC, Sunnyvale, CA, USA). 


\section{Measurement of lipid peroxidation in hippocampal homogenates}

The effects of $\mathrm{Cd}$ and/or DMS on lipid peroxidation levels in control, DMS-, Cd-, and Cd-DMS-treated rats ( $n=5$ in each group) were assessed by measuring malondialdehyde (MDA) formation using the Bioxytech MDA586 kit (Oxis Research, Portland, OR, USA). Briefly, bilateral hippocampi were collected using a surgical blade and the left part was homogenized in $20 \mathrm{mM}$ PBS ( $\mathrm{pH}$ 7.4) containing $5 \mathrm{mM}$ butylated hydroxytoluene. After centrifugation of the homogenates at $3000 \times g$ for $10 \mathrm{~min}$ at $4^{\circ} \mathrm{C}$, the supernatants were collected. For each reaction, $10 \mu \mathrm{L}$ of probucol and $640 \mu \mathrm{L}$ of diluted $\mathrm{R} 1$ reagent (1:3 of methanol: $N$-methyl-2-phenylindole) were added and mixed with $150 \mu \mathrm{L}$ of $12 \mathrm{~N} \mathrm{HCl}$. Each reaction was incubated at $45^{\circ} \mathrm{C}$ for $60 \mathrm{~min}$ and centrifuged at $10,000 \times \mathrm{g}$ for $10 \mathrm{~min}$. The supernatant was collected and MDA formation was determined by measuring the absorbance at $586 \mathrm{~nm}$. MDA data were normalized to the protein concentration of each sample.

\section{Protein carbonyl levels}

To elucidate the effects of $\mathrm{Cd}$ and/or DMS on protein modification, carbonylation of proteins as a result of oxidative stress was determined in control, DMS-, Cd-, and Cd-DMS-treated rats ( $n=5$ in each group) by the Levine method [18]. The color intensity of the supernatant was measured at $370 \mathrm{~nm}$ using a spectrophotometer against $2 \mathrm{M} \mathrm{HCl}$. Carbonyl content was calculated using the molar extinction coefficient $\left(21 \times 10^{3} \mathrm{~L} / \mathrm{mol} \mathrm{cm}\right)$, and results were expressed as nmol/mg of protein.

\section{Measurement of antioxidant activity in hippocampal homogenates}

To elucidate the effects of $\mathrm{Cd}$ and/or DMS on $\mathrm{Cu}, \mathrm{Zn}$ superoxide dismutase 1 (SOD1), catalase (CAT), and glutathione peroxidase (GPx), the activity of these enzymes was measured in control, DMS-, Cd-, and CdDMS-treated rats ( $n=7$ in each group). Briefly, the right part of the hippocampus (matching the right part used for measurement of lipid peroxidation) was homogenized in $10 \mathrm{mM}$ Tris buffer containing $1 \mathrm{mM}$ EDTA and $1 \mathrm{mM}$ PMSF. The homogenates were centrifuged at $600 \times g$ for $10 \mathrm{~min}$, and then centrifuged at $13,000 \times g$ for $20 \mathrm{~min}$ at $4^{\circ} \mathrm{C}$.

SOD1 activity was measured by monitoring its capacity to inhibit the reduction of ferricytochrome $c$ by xanthine/xanthine oxidase as described by McCord and Fridovich [19]. SOD1 activity staining was performed by electrophoresis in 10\% native polyacrylamide gels and visualized as described by Beauchamp and Fridovich [20]. Briefly, the gel was soaked in $2.45 \mathrm{mM}$ nitroblue tetrazolium solution for $15 \mathrm{~min}$, followed by $30 \mathrm{~min}$ in $28 \mathrm{mM}$ $N, N, N^{\prime \prime}, N^{\prime \prime}$-tetramethylethylene diamine and $28 \mu \mathrm{M}$ riboflavin in $0.36 \mathrm{mM}$ potassium phosphate buffer ( $\mathrm{pH}$ 7.8). The gel was exposed to a fluorescent light source until the bands showed maximum resolution.

CAT activity was assayed at $25^{\circ} \mathrm{C}$ by determining the rate of $\mathrm{H}_{2} \mathrm{O}_{2}$ degradation in $10 \mathrm{mM}$ of potassium phosphate buffer ( $\mathrm{pH} 7.0$ ) according to Aebi's method [21]. An extinction coefficient of $43.6 \mathrm{mM} / \mathrm{cm}$ was used for the calculations. One unit is defined as 1 pmol of $\mathrm{H}_{2} \mathrm{O}_{2}$ consumed per min and the specific activity is reported as units per mg of protein.

GPx activity was assayed by measuring nicotinamide adenine dinucleotide phosphate (NADPH) oxidation with $t$-butyl-hydroperoxide as a substrate according to the method of Maral et al. [22]. Briefly, the reaction was carried out at $25^{\circ} \mathrm{C}$ in $600 \mu \mathrm{L}$ of a solution containing $100 \mathrm{mM}$ potassium phosphate buffer ( $\mathrm{pH} 7.7), 1 \mathrm{mM}$ EDTA, $0.4 \mathrm{mM}$ sodium azide, $2 \mathrm{mM}$ glutathione, $0.1 \mathrm{mM}$ $\mathrm{NADPH}, 0.62 \mathrm{U}$ of glutathione reductase, and $50 \mu \mathrm{L}$ of homogenate.

\section{Measurement of glutathione-related enzymes in hippocampal homogenates}

The effects of $\mathrm{Cd}$ and/or DMS on glutathione-related enzymes in the hippocampus of control, DMS-, Cd-, and Cd-DMS-treated rats ( $n=5$ in each group) were investigated using the tissue samples obtained for the measurement of protein carbonyl levels. Glutathione-S-transferase (GST) activity was determined spectrophotometrically using 1-chloro-2,4-dinitrobenzene as a substrate [23]. Glutathione reductase (GR), which has been shown to utilize NADPH to convert oxidized glutathione (GSSG) to the reduced form (GSH), was assayed by the method of Horn and Burns [24].

\section{Statistical analysis}

All data are expressed as mean \pm standard error of the mean (SEM). To determine the effects of Cd and DMS, differences between the means were statistically analyzed using two-way analysis of variance (ANOVA) with repeated measures and Bonferroni's post hoc test.

\section{Results}

\section{Quantification of Cd content in kidney and brain tissues}

The ICP-MS method was used to determine Cd concentrations in serum, kidney, and hippocampal tissues. Cd concentrations in serum, kidney, and hippocampal tissues were similar in the control and DMS-treated groups. In the $\mathrm{Cd}$-treated group, $\mathrm{Cd}$ concentrations in the serum and kidney were significantly higher than those in the control group. In contrast, there was no significant difference in the $\mathrm{Cd}$ concentration in the hippocampus between the control and DMS-treated groups, although the level was increased 1.57-fold in the control group. In the Cd-DMS-treated group, $\mathrm{Cd}$ concentrations 
in the serum and kidneys were significantly lower than those in the Cd-treated group (Table 1).

\section{Effects of Cd and/or DMS on ROS formation in hippocampal homogenates}

DCF fluorescence levels were similar in the control and DMS-treated groups. DCF fluorescence was significantly increased (1.71-fold) in the Cd-treated group in comparison with that of the control group. However, the MDA level of the Cd-DMS-treated group was significantly decreased to $74.4 \%$ of that of the Cd-treated group (Figure 1A).

\section{Effects of $\mathrm{Cd}$ and/or DMS on protein carbonyl levels in hippocampal homogenates}

Protein carbonyl levels were similar in the control and DMS-treated groups. However, the protein carbonyl level of the Cd-treated group was significantly increased (2.4-fold) in comparison with that of the control group. The protein carbonyl level of the Cd-DMS-treated group was significantly decreased to $57.4 \%$ of that of the $\mathrm{Cd}$ treated group (Figure 1B).

\section{Effects of $\mathrm{Cd}$ and/or DMS on lipid peroxidation in hippocampal homogenates}

MDA levels in hippocampal homogenates were 25.8 and $25.4 \mathrm{nmol} / \mathrm{mg}$ protein in the control and DMS-treated groups, respectively. The MDA level of the $\mathrm{Cd}$-treated group was 2.2-fold higher than that of the control group. However, the MDA level of the Cd-DMS-treated group was significantly lower $(39.1 \mathrm{nmol} / \mathrm{mg}$ protein) than that of the Cd-treated group (Figure $1 \mathrm{C}$ ).

\section{Effects of Cd and/or DMS on SOD1, CAT, and GPx activities in hippocampal homogenates}

SOD1, CAT, and GPx activities in the control group were $15.61,1.739$, and $198.1 \mathrm{U} / \mathrm{mg}$ protein, respectively. In the DMS-treated group, SOD1 and GPx activities were slightly higher than those in the control group. However, CAT activity was lower than that of the control group. In the Cd-treated group, SOD1, CAT, and GPx activities were significantly lower than those in the control group. The effect of Cd exposure on SOD1 activity was its most pronounced effect. SOD1, CAT, and
GPx activities in the Cd-DMS-treated group were significantly higher than those in the Cd-treated group, and the greatest increase was in GPx activity (Figure 2).

Effects of Cd and/or DMS on glutathione-related enzymes in hippocampal homogenates

In the control and DMS-treated groups, GSH level, TSH (total sulfhydryl groups) level, and the activities of GR and GST were similar in the hippocampal homogenates. In the Cd-treated group, TSH level and GR activity were significantly decreased to $53.5 \%$ and $37.8 \%$ of those of the control group, respectively. In contrast, GST activity in the Cd-treated group was significantly increased to $147.7 \%$ of that of the control group. In the Cd-DMStreated group, TSH level and GR activity were significantly increased to $172.9 \%$ and $174.7 \%$ of those of the control group, respectively. GST activity in the CdDMS-treated group was significantly decreased to $58.5 \%$ of that of the Cd-treated group (Figure 3).

\section{Discussion}

Cd causes toxicity by disturbing the cellular homeostasis of essential metal ions such as copper and zinc. In addition, $\mathrm{Cd}$ affects antioxidant enzymes, which use copper and zinc, through oxidation or peroxidation in the brain [25]. In contrast, DMS has high ferric-reducing ability and contains high levels of phenolic compounds [13]. Therefore, we investigated the effects of DMS on $\mathrm{Cd}$-induced oxidative stress in the hippocampus. Chronic administration of $\mathrm{Cd}$ significantly increased $\mathrm{Cd}$ levels in kidney and hippocampal tissues. Supplementation with DMS markedly decreased the Cd concentration in the kidneys, but Cd levels were only slightly decreased in hippocampal tissue.

Cd can affect the integrity and permeability of the vascular endothelium, penetrate the blood-brain barrier, and accumulate in the brain [26-28]. In this study, we measured mitochondrial ROS formation after $\mathrm{Cd}$ exposure based on the conversion of DCFH-DA to DCF. Exposure to $\mathrm{Cd}$ significantly increased ROS formation. In addition, we observed decreased TSH content and increased protein carbonylation because the oxidative effect of $\mathrm{Cd}$ is associated mainly with the depletion of sulfhydryl group-containing compounds [29]. Cd administration

Table 1 Effects of cadmium (Cd) and/or Dendropanax morbifera stem extract (DMS) on Cd concentration ( $\mu \mathrm{g} / \mathrm{g}$ ) in the blood and hippocampal and kidney tissues of rats

\begin{tabular}{llll}
\hline Tissue & Control & DMS & Cd \\
\hline Blood & $4.12 \pm 1.12$ & $3.48 \pm 0.84$ & $39.7 \pm 4.12^{*}$ \\
Hippocampus & $0.014 \pm 0.0009$ & $0.012 \pm 0.0012$ & $0.022 \pm 0.0012$ \\
Kidney & $0.015 \pm 0.0028$ & $0.014 \pm 0.0041$ & $4.365 \pm 1.4105^{*}$ \\
\hline
\end{tabular}

* Indicates a significant difference between the control and Cd groups $(P<0.05) ;{ }^{\#}$ Indicates a significant difference between the $C d$ and $C d / D M S$ groups $(P<0.05$; $n=7$ per group). The data represent the mean \pm standard error of the mean (SEM). 

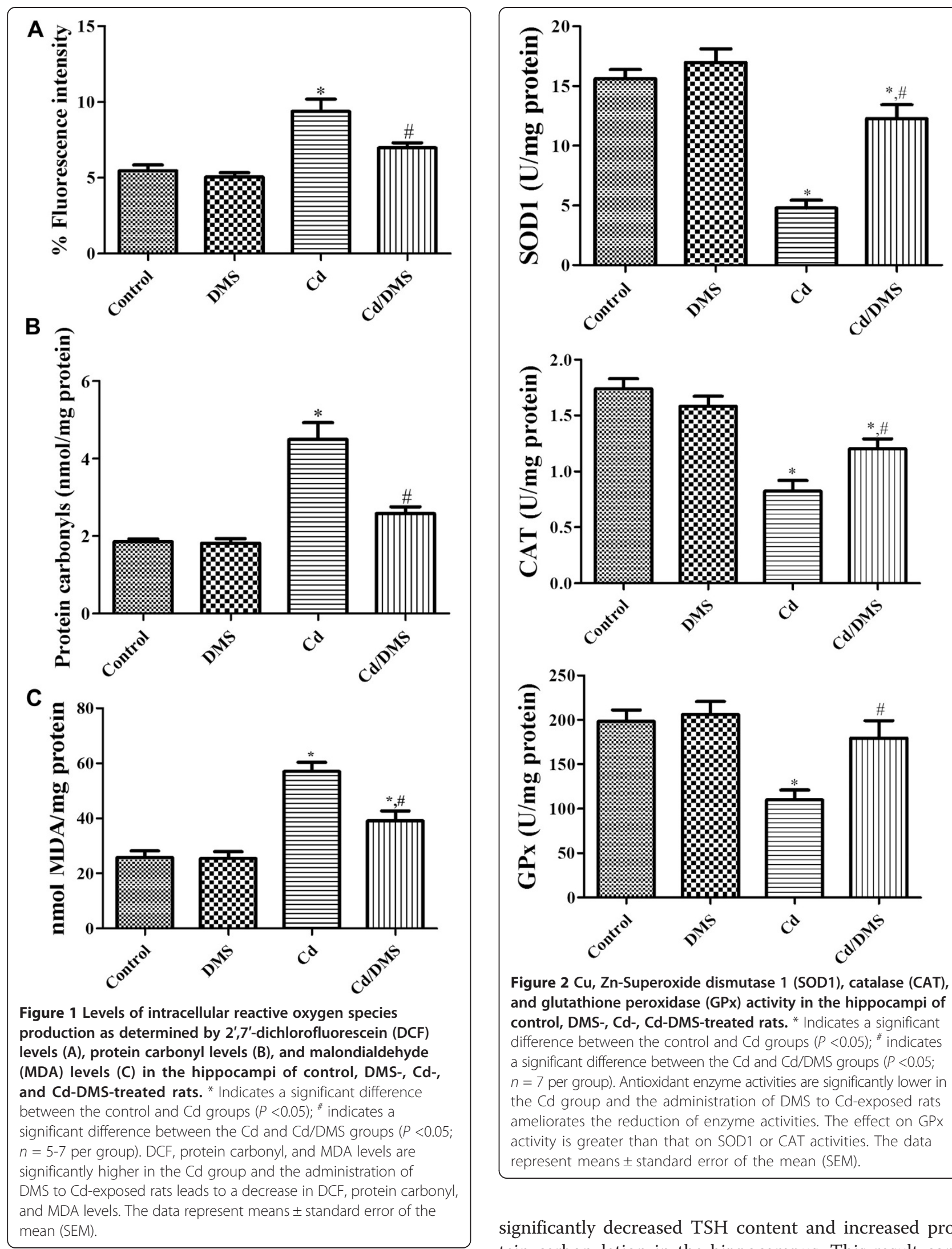

Figure $2 \mathrm{Cu}, \mathrm{Zn}$-Superoxide dismutase 1 (SOD1), catalase (CAT), and glutathione peroxidase (GPx) activity in the hippocampi of control, DMS-, Cd-, Cd-DMS-treated rats. * Indicates a significant difference between the control and $\mathrm{Cd}$ groups $(P<0.05) ;{ }^{*}$ indicates a significant difference between the $\mathrm{Cd}$ and $\mathrm{Cd} / \mathrm{DMS}$ groups $(P<0.05$; $n=7$ per group). Antioxidant enzyme activities are significantly lower in the $\mathrm{Cd}$ group and the administration of DMS to Cd-exposed rats ameliorates the reduction of enzyme activities. The effect on GPX activity is greater than that on SOD1 or CAT activities. The data represent means \pm standard error of the mean (SEM).

significantly decreased TSH content and increased protein carbonylation in the hippocampus. This result confirmed those of previous studies, which showed that $\mathrm{Cd}$ 

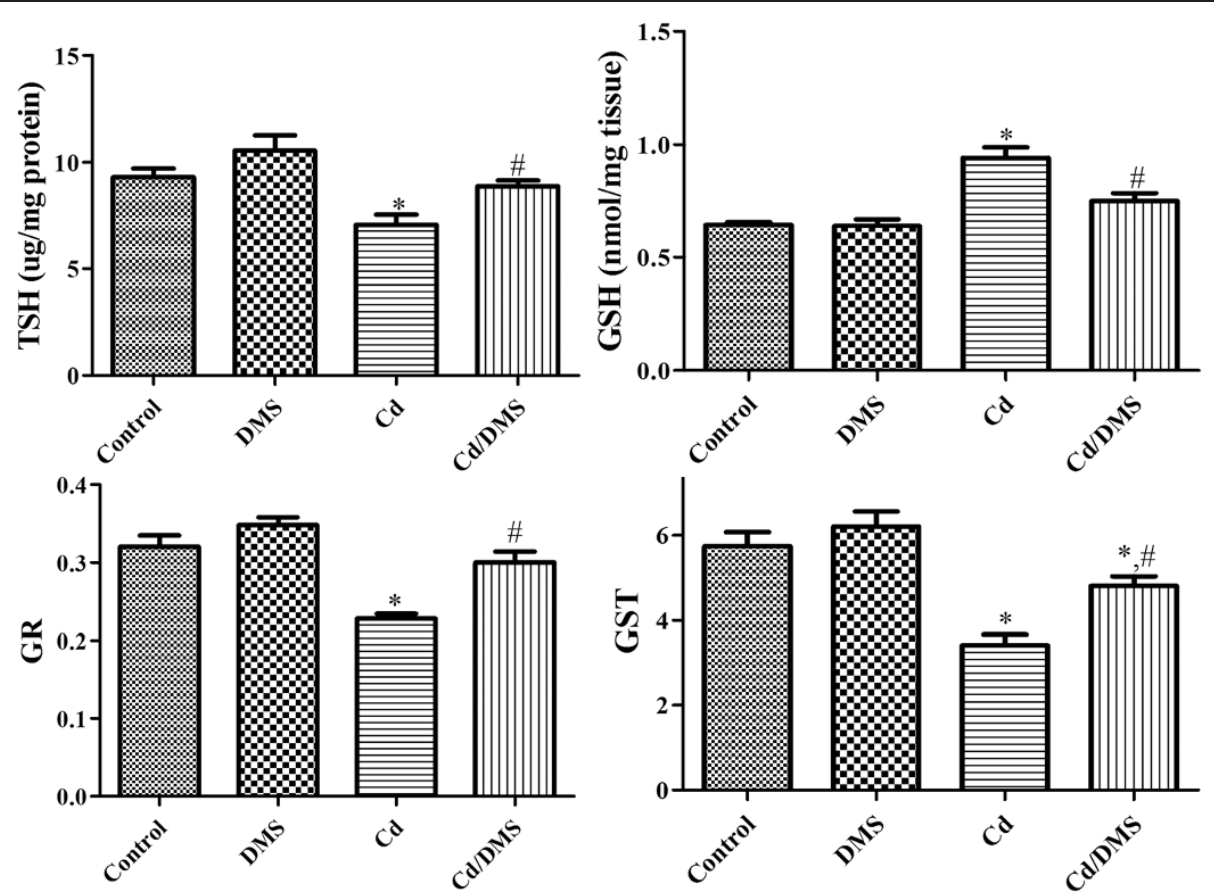

Figure 3 Total sulfhydryl groups (TSH), reduced glutathione (GSH), glutathione reductase (GR), and glutathione-S-transferase (GST) in the hippocampi of control, DMS-, Cd-, Cd/DMS-treated rats. * Indicates a significant difference between the control and $C d$ groups $(P<0.05)$; \# indicates a significant difference between the $\mathrm{Cd}$ and $\mathrm{Cd}$ /DMS groups $(P<0.05 ; n=5$ per group). GR activity, TSH levels, and GSH levels are significantly increased after exposure to Cd, while GST activity is significantly increased. The administration of DMS to Cd-exposed rats ameliorates or reverses the changes of enzyme activities or levels. The data represent means \pm standard error of the mean (SEM).

administration significantly increased ROS-mediated reactions in the brain, including the hippocampus [30], and kidney [31]. We also estimated lipid peroxidation by measuring MDA level, which is a major oxidation product of peroxidized polyunsaturated fatty acids [32]. Repeated administration of Cd significantly increased MDA levels in the hippocampus. This result is consistent with previous studies showing that exposure to $\mathrm{Cd}$ for 30 days significantly increases MDA levels in hippocampal tissue $[33,34]$. However, supplementation with DMS significantly reduced MDA levels in the hippocampus. This suggests that DMS potently inhibits Cd-induced lipid peroxidation in the hippocampus. This result is in accordance with a recent study showing that rutin isolated from Dendropanax morbifera Léveille significantly decreases rotenone-induced generation of reactive oxygen species in SH-SY5Y cells [14].

In this study, we also determined the effects of DMS and/or Cd on the activity of SOD1, CAT, and GPx in the hippocampus because $\mathrm{Cd}$ has been shown to inhibit antioxidant enzymes [33-38]. We found that Cd exposure for 4 weeks significantly reduced the activities of SOD1, CAT, and GPx in the hippocampus. These data are in agreement with those of previous studies showing that GPx, SOD1, Mn-SOD, and CAT activities in the hippocampus are significantly decreased after Cd exposure for 30 days [33,34]. Cd attacks intracellular sulfhydryl groups and disrupts organelles [39], because most antioxidant enzymes become inactive when $\mathrm{Cd}$ binds to their active sites [40]. Supplementation with DMS prevented the Cd-induced inhibition of SOD1, CAT, and GPx activities in the hippocampus, suggesting that the antioxidant effects of DMS may attenuate Cd-induced neurotoxicity in the hippocampus.

We focused on glutathione-related enzymes because the increase in activity after DMS treatment in Cdexposed rats was most prominent for GPx, among the antioxidative enzymes. Exposure to Cd significantly decreased GR activity, TSH level, and GSH level, while GST activity was significantly increased. The decrease of GR activity, TSH level, and GSH level after Cd exposure could be responsible for increased ROS levels and subsequent lipid peroxidation and protein carbonylation in the brain, because GSH can directly scavenge ROS or act as a substrate for GPx and GST in the detoxification of hydrogen peroxide [41]. DMS administration significantly ameliorated changes in glutathione-related enzymes in the hippocampus caused by $\mathrm{Cd}$ exposure, and this effect may be associated with direct reductions in ROS levels. 


\section{Conclusion}

The administration of DMS promotes the excretion of $\mathrm{Cd}$ from the kidney and ameliorates $\mathrm{Cd}$-induced increases in ROS, lipid peroxidation, and protein carbonyl levels, which are modified by oxidative stress. In addition, DMS efficiently attenuates Cd-induced deficits in SOD1, CAT, GPx, and glutathione-related enzyme activities in the hippocampus.

\section{Competing interests}

The authors declare that they have no competing interests.

\section{Authors' contributions}

WK, DWK, DYY, JHC, HYJ, SMN, JWK, YSY, and IKH conceived the study, designed and conducted the experiments, and drafted the manuscript. SMH and DWK made the Dendropanax morbifera Leveille extract. JHC and SMM participated in designing and discussing the study. All authors have read and approved the final manuscript.

\section{Acknowledgements}

This Research was supported by High Value-added Food Technology Development Program, Ministry for Agriculture, Food and Rural Affairs, Republic of Korea (112106-022-HD020)

\section{Author details}

'Department of Anatomy and Cell Biology, and Research Institute for Veterinary Science, College of Veterinary Medicine, Seoul National University, Seoul 151-742, South Korea. ${ }^{2}$ Department of Biochemistry and Molecular Biology, Research Institute of Oral Sciences, College of Dentistry, Kangneung-Wonju National University, Gangneung $210-702$, Korea. ${ }^{3}$ Central Research Center, Egreen Co. Ltd, Seongnam 463-862, South Korea. ${ }^{4}$ Department of Anatomy, College of Veterinary Medicine, Kangwon National University, Chuncheon 200-701, South Korea. ${ }^{5}$ Department of Neurosurgery, Dongtan Sacred Heart Hospital, College of Medicine, Hallym University, Hwaseong 445-170, South Korea.

\section{Received: 7 October 2014 Accepted: 17 October 2014}

Published: 31 October 2014

\section{References}

1. Kim SH, Hang YS, Han JG, Chung HG, Lee SW, Cho KJ: Genetic variation and population structure of Dendropanax morbifera Lév. (Araliaceae) in Korea. Silvae Genetica 2006, 55:7-13.

2. Park BY, Min BS, Oh SR, Kim JH, Kim TJ, Kim DH, Bae KH, Lee HK: Isolation and anticomplement activity of compounds from Dendropanax morbifera. J Ethnopharmacol 2004, 90:403-408.

3. Chung IM, Kim MY, Park WH, Moon HI: Antiatherogenic activity of Dendropanax morbifera essential oil in rats. Pharmazie 2009, 64:547-549.

4. Chung IM, Song HK, Kim SJ, Moon HI: Anticomplement activity of polyacetylenes from leaves of Dendropanax morbifera Léveille. Phytother Res 2011, 25:784-786.

5. Moon HI: Antidiabetic effects of dendropanoxide from leaves of Dendropanax morbifera Leveille in normal and streptozotocin-induced diabetic rats. Hum Exp Toxicol 2011, 30:870-875.

6. López E, Arce C, Oset-Gasque MJ, Cañadas S, González MP: Cadmium induces reactive oxygen species generation and lipid peroxidation in cortical neurons in culture. Free Radic Biol Med 2006, 40:940-951.

7. Nawrot T, Plusquin M, Hogervorst J, Roels HA, Celis H, Thijs L, Vangronsveld J, Van Hecke E, Staessen JA: Environmental exposure to cadmium and risk of cancer: a prospective population-based study. Lancet Oncol 2006, 7:119-126.

8. Galán A, García-Bermejo L, Troyano A, Vilaboa NE, Fernández C, de Blas E, Aller $\mathrm{P}$ : The role of intracellular oxidation in death induction (apoptosis and necrosis) in human promonocytic cells treated with stress inducers (cadmium, heat, X-rays). Eur J Cell Biol 2001, 80:312-320.

9. Bauer $V$, Bauer $F$ : Reactive oxygen species as mediators of tissue protection and injury. Gen Physiol Biophys 1999, 18 Spec No:7-14.

10. Ates I, Suzen HS, Aydin A, Karakaya A: The oxidative DNA base damage in testes of rats after intraperitoneal cadmium injection. Biometals 2004, 17:371-377
11. Gałazyn-Sidorczuk M, Brzóska MM, Jurczuk M, Moniuszko-Jakoniuk J: Oxidative damage to proteins and DNA in rats exposed to cadmium and/or ethanol. Chem Biol Interact 2009, 180:31-38.

12. Usai C, Barberis A, Moccagatta L, Marchetti C: Pathways of cadmium influx in mammalian neurons. J Neurochem 1999, 72:2154-2161.

13. Hyun TK, Kim MO, Lee H, Kim Y, Kim E, Kim JS: Evaluation of anti-oxidant and anti-cancer properties of Dendropanax morbifera Léveille. Food Chem 2013, 141:1947-1955.

14. Park SE, Sapkota K, Choi JH, Kim MK, Kim YH, Kim KM, Kim KJ, Oh HN, Kim SJ, Kim S: Rutin from Dendropanax morbifera Leveille protects human dopaminergic cells against rotenone induced cell injury through inhibiting JNK and p38 MAPK signaling. Neurochem Res 2014, 39:707-718.

15. Lebel CP, Ali SF, McKee M, Bondy SC: Organometal-induced increases in oxygen reactive species: the potential of $2^{\prime}, 7^{\prime}$-dichlorofluorescin diacetate as an index of neurotoxic damage. Toxicol Appl Pharmacol 1990, 104:17-24

16. Hwang IK, Yoo KY, Kim DW, Lee CH, Choi JH, Kwon YG, Kim YM, Choi SY, Won $\mathrm{MH}$ : Changes in the expression of mitochondrial peroxiredoxin and thioredoxin in neurons and glia and their protective effects in experimental cerebral ischemic damage. Free Radic Biol Med 2010, 48:1242-1251.

17. Bradford MM: A rapid and sensitive method for the quantitation of microgram quantities of protein utilizing the principle of protein-dye binding. Anal Biochem 1976, 72:248-254.

18. Levine RL, Garland D, Oliver CN, Amici A, Climent I, Lenz AG, Ahn BW, Shaltiel S, Stadtman ER: Determination of carbonyl content in oxidatively modified proteins. Methods Enzymol 1990, 186:464-478.

19. McCord JM, Fridovich I: Superoxide dismutase: an enzymic function for erythrocuprein (hemocuprein). J Biol Chem 1969, 244:6049-6055.

20. Beauchamp C, Fridovich I: Superoxide dismutase: improved assays and an assay applicable to acrylamide gels. Anal Biochem 1971, 44:276-287.

21. Aebi H: Catalase in vitro. Methods Enzymol 1984, 105:121-126.

22. Maral J, Puget K, Michelson AM: Comparative study of superoxide dismutase, catalase and glutathione peroxidase levels in erythrocytes of different animals. Biochem Biophys Res Commun 1977, 77:1525-1535.

23. Habig WH, Jakoby WB, Guthenberg C, Mannervik B, Vander Jagt DL: 2-Propylthiouracil does not replace glutathione for the glutathione transferases. J Biol Chem 1984, 259:7409-7410.

24. Horn HD, Burns FH: Methods of Enzymatic Analysis. New York: (ed. Bergmeyer HV) Academic Press; 1978:875-879.

25. Tandon SK, Singh S, Prasad S, Khandekar K, Dwivedi VK, Chatterjee M, Mathur N: Reversal of cadmium induced oxidative stress by chelating agent, antioxidant or their combination in rat. Toxicol Lett 2003, 145:211-217.

26. Yoshida S: Re-evaluation of acute neurotoxic effects of $\mathrm{Cd}^{2+}$ on mesencephalic trigeminal neurons of the adult rat. Brain Res 2001, 892:102-110.

27. Méndez-Armenta M, Ríos C: Cadmium neurotoxicity. Environ Toxicol Pharmacol 2007, 23:350-358.

28. Shukla A, Shukla GS, Srimal RC: Cadmium-induced alterations in bloodbrain barrier permeability and its possible correlation with decreased microvessel antioxidant potential in rat. Hum Exp Toxicol 1996, 15:400-405.

29. Rikans LE, Yamano T: Mechanisms of cadmium-mediated acute hepatotoxicity. J Biochem Mol Toxicol 2000, 14:110-117.

30. Abdalla FH, Schmatz R, Cardoso AM, Carvalho FB, Baldissarelli J, de Oliveira JS, Rosa MM, Gonçalves Nunes MA, Rubin MA, da Cruz IB, Barbisan F, Dressler VL, Pereira LB, Schetinger MR, Morsch VM, Gonçalves JF, Mazzanti CM: Quercetin protects the impairment of memory and anxiogenic-like behavior in rats exposed to cadmium: Possible involvement of the acetylcholinesterase and $\mathrm{Na}+, \mathrm{K}+-$ ATPase activities. Physiol Behav 2014, 135:152-167.

31. Pari L, Murugavel P, Sitasawad SL, Kumar KS: Cytoprotective and antioxidant role of diallyl tetrasulfide on cadmium induced renal injury: an in vivo and in vitro study. Life Sci 2007, 80:650-658.

32. Demir HA, Kutluk T, Ceyhan M, YağCı-Küpeli B, Akyüz C, Cengiz B, Varan A, Kara A, Yalçın B, Seçmeer G, Büyükpamukçu M: Comparison of sulbactam-cefoperazone with carbapenems as empirical monotherapy for febrile neutropenic children with lymphoma and solid tumors. Pediatr Hematol Oncol 2011, 28:299-310.

33. Amara S, Douki T, Garrel C, Favier A, Ben Rhouma K, Sakly M, Abdelmelek H: Effects of static magnetic field and cadmium on oxidative stress and 
DNA damage in rat cortex brain and hippocampus. Toxicol Ind Health 2011, 27:99-106.

34. Kanter M, Unsal C, Aktas C, Erboga M: Neuroprotective effect of quercetin against oxidative damage and neuronal apoptosis caused by cadmium in hippocampus. Toxicol Ind Health doi:10.1177/0748233713504810.

35. Paniagua-Castro N, Escalona-Cardoso G, Madrigal-Bujaidar E, Martínez-Galero E, Chamorro-Cevallos G: Protection against cadmium-induced teratogenicity in vitro by glycine. Toxicol In Vitro 2008, 22:75-79.

36. Pari L, Murugavel P: Diallyl tetrasulfide improves cadmium induced alterations of acetylcholinesterase, ATPases and oxidative stress in brain of rats. Toxicology 2007, 234:44-50.

37. Minami A, Takeda A, Nishibaba D, Takefuta S, Oku N: Cadmium toxicity in synaptic neurotransmission in the brain. Brain Res 2001, 894:336-339.

38. Luchese C, Brandão R, de Oliveira R, Nogueira CW, Santos FW: Efficacy of diphenyl diselenide against cerebral and pulmonary damage induced by cadmium in mice. Toxicol Lett 2007, 173:181-190.

39. Valko $M$, Morris $H$, Cronin MT: Metals, toxicity and oxidative stress. Curr Med Chem 2005, 12:1161-1208.

40. Quig D: Cysteine metabolism and metal toxicity. Altern Med Rev 1998 , 3:262-270.

41. Lu SC: Glutathione synthesis. Biochim Biophys Acta 2013, 1830:3143-3153.

\section{doi:10.1186/1472-6882-14-428}

Cite this article as: Kim et al:: Dendropanax morbifera Léveille extract facilitates cadmium excretion and prevents oxidative damage in the hippocampus by increasing antioxidant levels in cadmium-exposed rats. BMC Complementary and Alternative Medicine 2014 14:428.

\section{Submit your next manuscript to BioMed Central and take full advantage of:}

- Convenient online submission

- Thorough peer review

- No space constraints or color figure charges

- Immediate publication on acceptance

- Inclusion in PubMed, CAS, Scopus and Google Scholar

- Research which is freely available for redistribution 